\title{
EFEITO DE APLICAÇÕES DE LODOS DE ESGOTO SOBRE OS TEORES DE METAIS PESADOS EM FOLHAS E GRÃOS DE MILHO(1)
}

\author{
Otacílio José Passos Rangel ${ }^{(2)}$, Carlos Alberto Silva ${ }^{(3)}$, Wagner \\ Bettiol $^{(4)}$ \& José Flávio Dynia ${ }^{(4)}$
}

\begin{abstract}
RESUMO
O lodo de esgoto é uma fonte importante de nutrientes para as culturas; contudo, os teores de metais pesados em sua constituição podem limitar seu uso em solos agrícolas. O objetivo deste estudo foi avaliar o efeito de doses de lodos de esgoto oriundos das Estações de Tratamento de Esgoto de Barueri (LB) e de Franca (LF), SP, sobre os teores de metais pesados em folhas e grãos de milho. 0 experimento foi realizado no Campo Experimental da Embrapa Meio Ambiente, em Jaguariúna (SP), no período de 1999 a 2001. Foram realizados três cultivos sucessivos de milho, com os seguintes tratamentos: testemunha absoluta; adubação mineral (NPK) recomendada para a cultura do milho, lodo de esgoto com base no teor de $\mathrm{N}$ para fornecer uma, duas, quatro e oito vezes a dose de $\mathrm{N}$ da adubação mineral. Avaliaram-se os teores totais (digestão nítrico-perclórica) de Cu, Mn, Ni, $\mathrm{Pb}$ e $\mathrm{Zn}$ em folhas e grãos de milho. A aplicação sucessiva dos lodos de esgoto acarretou aumento nos teores de $\mathrm{Mn}$ e $\mathrm{Zn}$ em folhas e grãos de milho. Em relação ao tratamento testemunha, a aplicação da dose mais elevada do LB (8LB) promoveu um incremento de até 270 e $625 \%$ e de 35 e $115 \%$ nos teores de Mn e Zn, respectivamente, nas folhas e grãos de milho. As folhas apresentaram maiores teores de metais pesados do que os grãos, o que envolve maior possibilidade de transferência de metais para a cadeia alimentar, caso essa parte da planta seja consumida. Essa elevação nos teores de metais pesados em folhas e grãos de milho, até à terceira aplicação dos lodos, não foi suficiente para atingir os níveis considerados fitotóxicos para o milho, tampouco para inviabilizar o uso dos grãos para o consumo humano.
\end{abstract}

Termos para indexação: biossólido, resíduo urbano-industrial, Zea mays L., poluição ambiental.

\footnotetext{
(1) Parte da Tese de Mestrado do primeiro autor, apresentada ao Departamento de Ciência do Solo, Universidade Federal de Lavras - UFLA. Recebido para publicação em fevereiro de 2005 e aprovado em maio de 2006.

(2) Doutorando do Departamento de Ciência do Solo, Universidade Federal de Lavras - UFLA. Caixa Postal 3037, CEP 37200-000 Lavras (MG). E-mail: otaciliorangel@yahoo.com.br

(3) Professor Adjunto do Departamento de Ciência do Solo, UFLA. E-mail: csilva@ufla.br

(4) Pesquisador da Embrapa Meio Ambiente. Rodovia SP 340, Km 127,5. Caixa Postal 69, CEP 13820-000 Jaguariúna (SP). Bolsista do CNPq. E-mail: bettiol@cnpma.embrapa.br; dynia@cnpma.embrapa.br
} 


\title{
SUMMARY: EFFECTS OF SEWAGE SLUDGE APPLICATIONS ON HEAVY METAL CONTENTS IN CORN LEAVES AND GRAINS
}

\begin{abstract}
Sewage sludge is an important source of nutrients for crops, although the heavy metal contents can limit its use in agricultural soils. The objective of this study was to evaluate the effects of doses of sewage sludge (from the Treatment Stations of Barueri (LB) and Franca (LF), São Paulo State, Brazil) on heavy metal concentration in corn leaves and grains. The experiment was carried out at the Experimental Area of the Embrapa Environment, in Jaguariúna, state of São Paulo, from 1999 to 2001. The following treatments were applied to three successive corn crops: control (no sewage sludge); mineral fertilization recommended for corn (NPK); application of sewage sludge corresponding to the supply of one, two, four and eight times the N applied in the NPK treatment. The total contents (nitric-perchloric digestion) of $\mathrm{Cu}, \mathrm{Mn}, \mathrm{Ni}, \mathrm{Pb}$ and $\mathrm{Zn}$ were measured in corn leaves and grains. The successive application of sewage sludge caused increases in the $\mathrm{Mn}$ and $\mathrm{Zn}$ contents in corn leaves and grains. In relation to the control treatment, the application of the highest dose of $L B(8 L B)$ promoted an increment of up to 270 and $625 \%$ of $\mathrm{Mn}$, and 35 and $115 \%$ of $\mathrm{Zn}$ concentration, respectively, in the corn leaves and grains. The corn leaves presented higher heavy metals contents than the grains, which implicate a greater possibility of metal transfer to the food chain in case this part of the plant is consumed. Until the third sludge application the heavy metal concentration observed in corn leaves were lower than the levels considered phytotoxic, and their concentration in corn grains were not high enough to make them unsuitable for human consumption.
\end{abstract}

Index terms: biosolid, urban-industrial residue, Zea mays L., environmental pollution.

\section{INTRODUÇÃO}

O lodo de esgoto gerado nas Estações de Tratamento de Esgoto (ETE) é rico em nutrientes e matéria orgânica, podendo ser utilizado na agricultura como fertilizante. Entretanto, por conter em sua composição diversos poluentes, como os metais pesados, o uso continuado e sem critérios técnicos na agricultura pode resultar em aumento nos teores desses elementos no solo (Oliveira \& Mattiazzo, 2001), principalmente de $\mathrm{Cd}, \mathrm{Zn}, \mathrm{Cu}, \mathrm{Ni}$ e $\mathrm{Pb}$, que são os metais mais encontrados nesse material (Logan \& Chaney, 1983). Esse acúmulo de metais pesados no solo é preocupante, visto que é grande o risco de eles serem transferidos para as diferentes espécies de plantas (McBride, 1995) e, portanto, capazes de entrar na cadeia trófica.

Os teores de metais pesados nos tecidos das plantas dependem do $\mathrm{pH}$ do solo, da natureza do metal, do teor de matéria orgânica e da capacidade do solo em reter cátions (Chang et al., 1987; Mc Bride, 1995). O padrão de acúmulo de metais em plantas cultivadas em solos adubados com lodo de esgoto inclui respostas negativas, positivas ou ausência de resposta ao acréscimo dos teores de metais em solo (Page et al., 1987). Diferentes padrões de acúmulo de metais pesados em plantas foram verificados nos estudos de Oliveira \& Mattiazzo (2001) e Martins et al. (2003). Nestes estudos, os efeitos de doses crescentes de lodo de esgoto sobre o teor de metais em cana-de-açúcar e milho apresentaram diferentes tipos de respostas, incluindo ajustes do tipo linear, assintótico e efeitos negativos ou inexistentes, em relação ao aumento dos teores de $\mathrm{Cu}, \mathrm{Fe}, \mathrm{Mn}$ e $\mathrm{Zn}$ em solo.
Para avaliar o potencial de acúmulo dos metais pesados adicionados ao solo via lodo de esgoto, têm sido propostas duas teorias: a do platô (plateau theory) e a da bomba relógio (sludge time bomb theory). De acordo com a primeira teoria, as concentrações de metais nos tecidos das plantas atingiriam um platô com o aumento dos teores totais dos metais pesados em solos adubados com lodo de esgoto, permanecendo nesse patamar até o término das aplicações (Corey et al., 1987; Chang et al., 1997). Esse tipo de resposta foi observado em experimento de campo conduzido por Corey et al. (1987), no qual, a partir de certo nível de metais pesados em solo, não se verificou maior acúmulo de metais no tecido das plantas, com o acréscimo das doses de lodo.

Por outro lado, e também em condições de campo, esse tipo de resposta não foi observado no estudo de Martins et al. (2003), que verificaram um aumento linear nos teores, ausência de resposta ou, um menor teor de $\mathrm{Zn}, \mathrm{Mn}$, $\mathrm{Cu}$ e Fe em folhas de milho com o aumento das doses aplicadas de lodo. Esse último padrão de resposta pode estar associado à teoria da "bomba relógio". Em determinadas situações em que o lodo de esgoto é utilizado como fonte de nutrientes para as plantas, os teores de metais pesados podem não alcançar o platô sugerido por Corey et al. (1987). De acordo com McBride (1995) e Chang et al. (1997), após o cessamento das aplicações de lodo de esgoto, com os processos de degradação do $\mathrm{C}$ orgânico e a acidificação natural do solo, os metais pesados, ora indisponíveis, passariam a formas solúveis e disponíveis às plantas.

O acúmulo de metais pesados no tecido vegetal varia de uma espécie para outra. Em geral, a 
seqüência decrescente de acúmulo de metais pesados em planta é: $\mathrm{Ni}>\mathrm{Zn}>\mathrm{Pb}>\mathrm{Mn}>\mathrm{Cu}$ (KabataPendias \& Pendias, 2001). As diferentes partes da planta comportam-se de modo distinto, de acordo com o elemento considerado e, em se tratando de lodo de esgoto, das fontes e doses utilizadas. Pierrisnard (1996) verificou que o $\mathrm{Zn}$ acumulou-se preferencialmente nos sabugos e folhas; o $\mathrm{Pb}$, em sabugos e colmos; o $\mathrm{Cr}$, nos sabugos e grãos; o Cd, nos sabugos, grãos e colmos; e o $\mathrm{Ni}$ e o $\mathrm{Cu}$, nos sabugos, grãos e raízes. Segundo Jing \& Logan (1992), os frutos, em relação às partes vegetativas das plantas, acumulam menores quantidades de metais pesados, daí o uso de lodo ser mais recomendado nos casos em que são colhidos os frutos, e a parte aérea das plantas não é utilizada na alimentação animal (Gardiner et al., 1995).

Este estudo teve como objetivo avaliar os efeitos de repetidas aplicações de duas fontes de lodo de esgoto sobre os teores de $\mathrm{Cu}, \mathrm{Mn}, \mathrm{Ni}, \mathrm{Pb}$ e $\mathrm{Zn}$ em folhas e grãos de milho, em condições de campo, em três cultivos sucessivos.

\section{MATERIAL E MÉTODOS}

O experimento foi realizado no Campo Experimental da Embrapa Meio Ambiente, localizado em Jaguariúna (SP), em um Latossolo Vermelho distroférrico textura argilosa, durante os anos de 1999 a 2001. As características físicas e químicas do solo $(0-20 \mathrm{~cm})$ da área experimental foram analisadas de acordo com os protocolos analíticos descritos em Silva (1999), sendo o teor de matéria orgânica $=25,5 \mathrm{~g} \mathrm{~kg}^{-1}$; argila $=450 \mathrm{~g} \mathrm{~kg}^{-1} ; \mathrm{pH}$ em água $=5,8 ; \mathrm{Ca}^{2+}=$ 27,5 mmol $_{\mathrm{c}} \mathrm{kg}^{-1} ; \mathrm{Mg}^{2+}=8,5$ mmol $_{\mathrm{c}} \mathrm{kg}^{-1} ; \mathrm{P}$ (Mehlich-1) $=3,5 \mathrm{mg} \mathrm{kg}-1 ; \mathrm{K}^{+}=1,51 \mathrm{mmol}_{\mathrm{c}} \mathrm{kg}^{-1} ; \mathrm{Al}^{3+}=$ $1 \mathrm{mmol}_{\mathrm{c}} \mathrm{kg}^{-1} ; \mathrm{H}+\mathrm{Al}=35 \mathrm{mmol}_{\mathrm{c}} \mathrm{kg}^{-1}, \mathrm{CTC}$ a pH 7,0 $=71 \mathrm{mmol}_{\mathrm{c}} \mathrm{kg}^{-1} \mathrm{e}$ saturação por bases (V) igual a $51 \%$.

Foram utilizados no estudo dois tipos de lodo de esgoto, um oriundo da ETE de Barueri, SP (Lodo de Barueri - LB), que trata esgoto doméstico e industrial, e outro oriundo da ETE de Franca, SP (Lodo de Franca - LF), que trata esgoto principalmente doméstico. Antes da aplicação no campo, foi coletada uma amostra representativa de cada partida dos lodos de esgoto utilizados nos diferentes cultivos do milho, para avaliação de suas composições químicas. Os teores dos elementos $\mathrm{P}, \mathrm{K}, \mathrm{Ca}, \mathrm{Mg}, \mathrm{Na}, \mathrm{S}, \mathrm{Mo}, \mathrm{Cr}, \mathrm{Mn}, \mathrm{Fe}$, $\mathrm{Co}, \mathrm{Ni}, \mathrm{Cu}, \mathrm{Zn}, \mathrm{Al}, \mathrm{Cd}, \mathrm{Pb}, \mathrm{Ag}, \mathrm{As}$ e $\mathrm{B}$ foram avaliados pelo método EPA 3051 (Abreu et al., 2001), com a digestão realizada em bloco digestor e determinação feita por espectrofotometria de emissão ótica com plasma acoplado por indução (ICP-OES). Os teores de sólidos voláteis foram determinados, pesando-se $2,5 \mathrm{~g}$ de amostras secas $\left(65^{\circ} \mathrm{C}\right)$ dos lodos de esgoto levadas à mufla a $500{ }^{\circ} \mathrm{C}$ por $4 \mathrm{~h}$ (Apha et al., 1992). $\mathrm{O} \mathrm{N}$ total foi quantificado em amostras dos lodos secas a $65{ }^{\circ} \mathrm{C}$ e submetidas à digestão sulfúrica, sendo o $\mathrm{N}$, a seguir, submetido a processo de destilação a vapor e quantificado por titulometria com $\mathrm{HCl} 0,01 \mathrm{~mol} \mathrm{~L}^{-1}$ (Bremner et al., 1996). O C orgânico foi determinado pelo método da titulação, após oxidação via úmida (Nelson \& Sommers, 1982) (Quadro 1).

O delineamento experimental adotado foi o de blocos ao acaso, com três repetições. Cada parcela media $10 \times 20$ m, com 12 linhas por parcela. As parcelas foram separadas com bordaduras com pelo menos $5 \mathrm{~m}$ de largura, sendo essa faixa do terreno cultivada com braquiária, que era roçada periodicamente. Os tratamentos consistiram da aplicação de quatro doses dos dois lodos de esgoto, além de uma testemunha absoluta (sem adição de lodo de esgoto e adubação mineral) e um tratamento com adubação mineral. Os tratamentos avaliados foram: (T) testemunha; (AM) adubação mineral (NPK) recomendada para a cultura do milho, efetuada com base nos resultados de análise de solo e considerando uma produtividade esperada de 8 t ha $^{-1}$ (Raij et al., 1997); (1N) aplicação dos lodos de esgoto, visando suprir a mesma quantidade de $\mathrm{N}$ do tratamento $\mathrm{AM}(1 \mathrm{LF}$ e $1 \mathrm{LB}) ;(2 \mathrm{~N})$ duas vezes as doses dos lodos do tratamento $1 \mathrm{~N}$ (2LB e $2 \mathrm{LF}) ;(4 \mathrm{~N})$ quatro vezes as doses dos lodos do tratamento $1 \mathrm{~N}$ (4LB e $4 \mathrm{LF})$ e $(8 \mathrm{~N})$ oito vezes as doses dos lodos do tratamento $1 \mathrm{~N}$ (8LB e 8LF). As doses de lodo de esgoto, aplicadas em base seca, foram calculadas a partir do teor de $\mathrm{N}$ nos lodos, considerando uma taxa de mineralização do N orgânico do lodo de 30 \%, e da necessidade de N do milho, seguindo as recomendações da Norma P 4230 (CETESB, 1999). No tratamento AM, utilizaram-se a fórmula 4-20-16 e uréia na adubação em cobertura. Os lodos foram distribuídos a lanço dentro das parcelas e incorporados ao solo a uma profundidade de $0-20 \mathrm{~cm}$ com auxílio de enxada rotativa. Nos tratamentos em que o lodo de esgoto foi aplicado, foi feita, quando necessária, uma suplementação com $\mathrm{KCl}$ para fornecer a quantidade de K necessária ao milho no plantio (Quadro 2).

A calagem foi realizada um mês antes do primeiro e do terceiro cultivo de milho, sendo a quantidade aplicada calculada individualmente para cada parcela experimental, de forma a manter o $\mathrm{pH}$ entre 5,5 e 5,7. Os cultivares de milho utilizados no estudo foram: $1^{\circ}$ cultivo - CATI AL $30 ; 2^{\circ}$ cultivo - híbrido AG 1043, e $3^{\circ}$ cultivo - híbrido SAVANA 133S. O primeiro cultivo foi instalado no campo em 05/04/99 (milho safrinha); o segundo em 13/12/99, e o terceiro em 30/ 10/2000. A semeadura do milho foi realizada uma semana após a incorporação dos lodos de esgoto. O milho foi semeado no espaçamento de $0,90 \mathrm{~m}$ entre linhas e $0,20 \mathrm{~m}$ entre plantas, não havendo, em nenhum dos cultivos, suplementação de água via irrigação. Os restos culturais foram retirados da área experimental após o término de cada ciclo de cultivo.

Os teores totais dos metais $\mathrm{Cu}, \mathrm{Mn}, \mathrm{Ni}, \mathrm{Pb}$ e $\mathrm{Zn}$ em solo (Quadro 3), foram avaliados em amostras coletadas na profundidade de $0-20 \mathrm{~cm}$, uma semana após a aplicação dos lodos e adubos ao solo, por meio 
Quadro 1. Características de amostras dos lodos de esgoto utilizados nos três cultivos de milho

\begin{tabular}{|c|c|c|c|c|c|c|}
\hline \multirow{2}{*}{ Atributo(1) } & \multicolumn{2}{|c|}{$1^{0}$ cultivo } & \multicolumn{2}{|c|}{$2^{\circ}$ cultivo } & \multicolumn{2}{|c|}{$3^{\circ}$ cultivo } \\
\hline & LB & $\mathbf{L F}$ & LB & $\mathbf{L F}$ & LB & LF \\
\hline pH (água) & 6,6 & 6,3 & 6,4 & 6,4 & 6,4 & 5,4 \\
\hline Teor de água (\%) & 66,4 & 83,0 & 80,2 & 82,4 & 71,2 & 82,7 \\
\hline Sólidos Voláteis (\%) & 43 & 60,5 & nd & nd & 56,8 & 72,5 \\
\hline $\mathrm{C}$ orgânico $\left(\mathrm{g} \mathrm{kg}^{-1}\right)$ & 248,2 & 305,1 & 271 & 374 & 292,9 & 382,4 \\
\hline $\mathrm{N}$ total $\left(\mathrm{g} \mathrm{kg}^{-1}\right)$ & 21,0 & 64,0 & 49,7 & 67,5 & 42,1 & 68,2 \\
\hline $\mathrm{P}\left(\mathrm{g} \mathrm{kg}^{-1}\right)$ & 15,9 & 16,0 & 31,2 & 21,3 & 26,9 & 12,9 \\
\hline $\mathrm{K}\left(\mathrm{g} \mathrm{kg}^{-1}\right)$ & 1,0 & 1,0 & 1,9 & 0,9 & 1,0 & 1,0 \\
\hline $\mathrm{Ca}\left(\mathrm{g} \mathrm{kg}^{-1}\right)$ & 40,3 & 29,2 & 22,8 & 16,8 & 47,8 & 24,8 \\
\hline $\mathrm{Mg}\left(\mathrm{g} \mathrm{kg}^{-1}\right)$ & 3,0 & 2,2 & 3,7 & 2,5 & 4,5 & 2,2 \\
\hline $\mathrm{Na}(\mathrm{g} \mathrm{kg}-1)$ & 0,5 & 0,5 & 0,6 & 0,6 & 0,5 & 0,9 \\
\hline $\mathrm{S}\left(\mathrm{mg} \mathrm{kg} \mathrm{k}^{-1}\right)$ & 13,4 & 16,3 & 10,8 & 13,3 & 17,1 & 15,7 \\
\hline Mo $\left(\mathrm{mg} \mathrm{kg}^{-1}\right)$ & $<0,01$ & $<0,01$ & $<1,0$ & $<1,0$ & $<0,01$ & $<0,01$ \\
\hline $\mathrm{Cr}\left(\mathrm{mg} \mathrm{kg}^{-1}\right)$ & 823,8 & 633,8 & 1.071 & 1.325 & $1.297,2$ & 1.230 \\
\hline $\operatorname{Mn}\left(\mathrm{mg} \mathrm{kg}^{-1}\right)$ & 429 & 349,3 & 335 & 267 & 418,9 & 232,5 \\
\hline $\mathrm{Fe}\left(\mathrm{mg} \mathrm{kg}^{-1}\right)$ & 54.181 & 33.793 & 32.500 & 31.700 & 37.990 & 24.176 \\
\hline Co $\left(\mathrm{mg} \mathrm{kg}^{-1}\right)$ & 12,2 & 5,0 & 10,5 & 4,9 & 9,3 & 4,8 \\
\hline $\mathrm{Ni}\left(\mathrm{mg} \mathrm{kg}^{-1}\right)$ & 518,4 & 54,7 & 483 & 74 & 605,8 & 72,4 \\
\hline $\mathrm{Cu}\left(\mathrm{mg} \mathrm{kg}^{-1}\right)$ & 1.058 & 239,8 & 1.046 & 359,0 & 953,0 & 240,9 \\
\hline $\mathrm{Zn}\left(\mathrm{mg} \mathrm{kg}^{-1}\right)$ & 2.821 & 1.230 & 3.335 & 1.590 & 3.372 & 1.198 \\
\hline $\mathrm{Al}\left(\mathrm{mg} \mathrm{kg}^{-1}\right)$ & 28.781 & 32.564 & 25.300 & 33.500 & 23.283 & 23.317 \\
\hline $\mathrm{Cd}\left(\mathrm{mg} \mathrm{kg}{ }^{-1}\right)$ & 12,8 & 3,32 & 9,5 & 2,0 & 9,4 & 2,05 \\
\hline $\mathrm{Pb}\left(\mathrm{mg} \mathrm{kg}^{-1}\right)$ & 364,4 & 199,6 & 233,0 & 118,0 & 348,9 & 140,5 \\
\hline $\mathrm{Ag}\left(\mathrm{mg} \mathrm{kg}{ }^{-1}\right)$ & $<0,01$ & $<0,01$ & $<1,0$ & $<1$ & $<0,01$ & $<0,01$ \\
\hline As $\left(\mathrm{mg} \mathrm{kg}^{-1}\right)$ & $<1,0$ & $<1,0$ & $<1,0$ & $<1,0$ & $<1,0$ & $<1,0$ \\
\hline $\mathrm{B}\left(\mathrm{mg} \mathrm{kg} \mathrm{kg}^{-1}\right)$ & 36,2 & 40,7 & 11,2 & 7,1 & 29,3 & 19,7 \\
\hline
\end{tabular}

(1) Valores dados em base de matéria seca. nd - não determinado; LB = Lodo da estação de tratamento do Esgoto de Barueri e LF de Franca.

Quadro 2. Quantidades de lodo de esgoto, NPK, $\mathrm{N}$ em cobertura e $\mathrm{K}_{2} \mathrm{O}$ aplicados nos três cultivos de milho

Tratamento $(1) \frac{\text { Lodo de esgoto }}{1^{\mathrm{o}} \text { cultivo } 2^{\mathrm{o}} \text { cultivo } 3^{\mathrm{o}} \text { cultivo }} \frac{\mathrm{NPK}(2-20-16)}{1^{\mathrm{o}} \text { cultivo } 2^{\mathrm{o}} \text { cultivo } 3^{\mathrm{o}} \text { cultivo }} \frac{\mathrm{K}_{2} \mathrm{O}}{1^{\mathrm{o}} \text { cultivo } 2^{\mathrm{o}} \text { cultivo } 3^{\mathrm{o}} \text { cultivo }}$

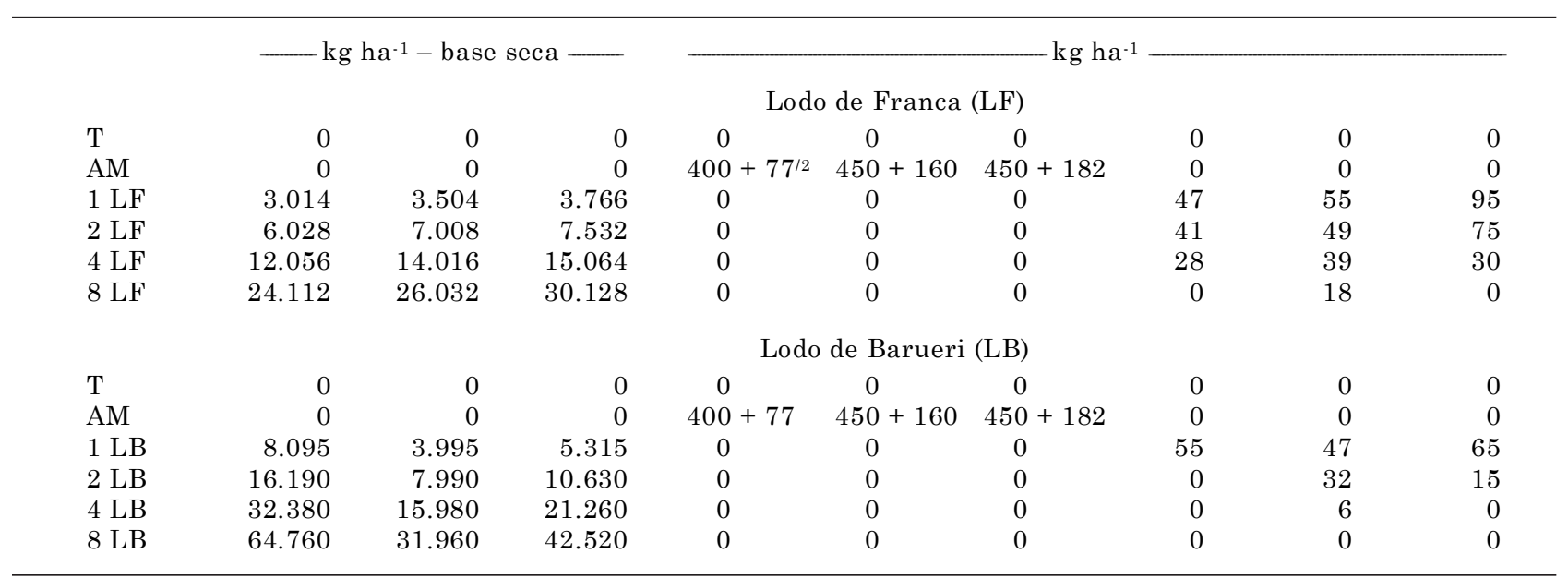

(1) $\mathrm{T}=$ testemunha absoluta; $\mathrm{AM}=$ adubação mineral (NPK); $1 \mathrm{LF}$ e $1 \mathrm{LB}=$ doses dos lodos de esgoto para fornecer a mesma quantidade de $\mathrm{N}$ do tratamento $\mathrm{AM} ; 2 \mathrm{LF}$ e $2 \mathrm{LB}=$ dois; $4 \mathrm{LF}$ e $4 \mathrm{LB}=$ quatro e $8 \mathrm{LF}$ e $8 \mathrm{LB}=$ oito vezes a dose dos lodos de esgoto descrita no tratamento $1 \mathrm{LF}$ e $1 \mathrm{LB} .{ }^{(2)}$ Quantidade de NPK aplicada no plantio + adubação nitrogenada em cobertura. 
de extração com água régia, utilizando-se a mistura dos ácidos $\mathrm{HCl}+\mathrm{HNO}_{3}$, v/v: 1:3, de acordo com os procedimentos recomendados pela International Organization for Standardisation-ISO (1995), com a determinação feita por ICP-OES.

As folhas utilizadas nas análises químicas foram amostradas, quando $50 \%$ das plantas de milho apresentavam pendoamento, aproximadamente dois meses após a semeadura, coletando-se o terço médio da folha oposta e abaixo da espiga (folha diagnose-FD), na área útil de cada parcela experimental (duas linhas centrais). Este material foi encaminhado para o laboratório, lavado seqüencialmente com água destilada, solução $0,1 \mathrm{~mol} \mathrm{~L}^{-1}$ de $\mathrm{HCl}$ e água deionizada. Após a lavagem, colocaram-se as folhas para secar em estufa com circulação forçada de ar a $65^{\circ} \mathrm{C}$. A amostragem de grãos foi feita no final do ciclo de cultivo com as plantas apresentando coloração amarelopalha (teor de água nos grãos próximo a $16 \%$ ), sendo coletadas trinta espigas de milho na área útil de cada parcela experimental para formar a amostra composta usada nas análises laboratoriais. As espigas foram secas em estufa de circulação forçada de ar a $65^{\circ} \mathrm{C}$, debulhadas e os grãos moídos. Nas amostras de folhas e grãos de milho, os teores totais dos metais $\mathrm{Cu}, \mathrm{Mn}, \mathrm{Ni}, \mathrm{Pb}$ e $\mathrm{Zn}$ foram determinados em extratos obtidos por digestão nítrico-perclórica (Tedesco et al., 1995), com recuperação do extrato com água destilada, em volume final de $20 \mathrm{~mL}$. As determinações analíticas foram efetuadas por ICP-OES.

As análises de regressão dos teores de metais pesados em folhas e grãos de milho, como variáveis dependentes das doses de lodo de esgoto aplicadas, foram realizadas por meio do aplicativo computacional SISVAR (Ferreira, 2000). Para os elementos em que a aplicação do lodo apresentou efeito significativo nos diferentes cultivos, são apresentadas as médias e as equações de regressão. Onde não se verificou efeito significativo da aplicação de lodo sobre os diferentes elementos avaliados, as médias são apresentadas com os respectivos desvios-padrão.

\section{RESULTADOS E DISCUSSÃO}

\section{Teores de metais pesados nos lodos}

O teor médio de metais pesados nos três lotes dos lodos das ETE's de Franca (LF) e Barueri (LB) (Quadro 1), foi, respectivamente: de 280; 283; 67; 153 e $1.340 \mathrm{mg} \mathrm{kg}^{-1}$ e $1.019 ; 394 ; 536 ; 315$ e $3.176 \mathrm{mg} \mathrm{kg}^{-1}$ de $\mathrm{Cu}, \mathrm{Mn}, \mathrm{Ni}, \mathrm{Pb}$ e Zn. Esses teores estão dentro do intervalo considerado normal por Webber et al. (1984), que estabeleceram limites máximos para Mn (500$3.000 \mathrm{mg} \mathrm{kg}^{-1}$ ), e inferiores, com exceção do Ni, para o lodo da ETE de Barueri, aos teores máximos de metais pesados permitidos no lodo de esgoto destinado ao uso agrícola no Estado de São Paulo (Norma P 4230,
CETESB, 1999): 4.300, 420, 840 e $7.500 \mathrm{mg} \mathrm{kg}^{-1}$ (base seca), respectivamente, para $\mathrm{Cu}, \mathrm{Ni}, \mathrm{Pb}$ e $\mathrm{Zn}$.

Uma vez que a norma $\mathrm{P} 4230$ da CETESB estabelece os critérios para o uso agrícola de lodo de esgoto no Estado de São Paulo, caso se confirme em outros lotes de lodo da ETE de Barueri, os teores de $\mathrm{Ni}$ verificados nesse estudo, esse material seria considerado impróprio para o uso agrícola no referido Estado. O maior teor de Ni no lodo de Barueri pode estar associado à natureza predominantemente industrial do esgoto tratado na ETE deste município, uma vez que a presença de Ni no lodo está relacionada com o tratamento de esgotos provenientes de indústrias que o utilizam na fabricação de ligas metálicas, baterias, componentes eletrônicos e em catalisadores (Bertoncini, 2002).

\section{Teores de metais pesados nas folhas}

Em relação ao teor de metais pesados no tecido foliar do milho, inicialmente, deve-se destacar que os teores considerados fitotóxicos são, em mg kg-1: de 100 a 150 para o $\mathrm{Mn} ; 50$ a 100 para o Ni; 3 a 20 para o $\mathrm{Cu}$; 500 a 1.500 para o Zn (Webber et al., 1984), e de 56 para o $\mathrm{Pb}$ (Kabata-Pendias \& Pendias, 2001). Os teores de metais pesados verificados no tecido foliar do milho indicaram, a partir dos dados máximos citados anteriormente, que os teores fitotóxicos não foram alcançados até à terceira aplicação de doses crescentes dos lodos oriundos de Barueri e Franca. Ainda assim, para os metais $\mathrm{Cu}, \mathrm{Pb}$ e $\mathrm{Zn}$, verificaramse incrementos em seus teores nas folhas de milho com a seqüência dos cultivos (Figura 1).

As quantidades de $\mathrm{Cu}$ adicionadas ao solo pela aplicação do LB foram elevadas, principalmente nas maiores doses, correspondendo a uma adubação de $68,5,33,4$ e $40,5 \mathrm{~kg} \mathrm{ha}^{-1} \mathrm{de} \mathrm{Cu}$, no $1^{\circ}, 2^{\circ}$ e $3^{\circ}$ cultivo, respectivamente. Dos metais avaliados, o $\mathrm{Cu}$ foi o que apresentou teores em folha dentro da faixa considerada fitotóxica; contudo, até o terceiro cultivo, não foram observados teores acima da faixa superior de toxidez. Apenas foram observados efeitos significativos da aplicação das doses dos lodos de esgoto nos teores foliares de $\mathrm{Cu}$ no $1^{\circ}$ cultivo-LB e no $3^{\circ}$ cultivo-LF, o que indica a ausência de resposta dos teores foliares deste metal pela aplicação das doses crescentes dos lodos em estudo. Essa ausência de resposta dos teores foliares de $\mathrm{Cu}$ à adição das doses crescentes de lodo de esgoto pode ser atribuída à forte complexação que esse elemento sofre pela matéria orgânica (Kabata-Pendias \& Pendias, 2001) e pelo antagonismo que ocorre entre o $\mathrm{Cu}$ e o $\mathrm{Zn}$ (adicionado ao solo em maior quantidade pelas duas fontes de lodo) na solução do solo (Faquin, 2001). Outro fator a ser considerado é que o $\mathrm{Cu}$ tende a acumular mais nas raízes, em relação às folhas, indicando que a menor resposta às adições de lodo de esgoto, em termos de teores de $\mathrm{Cu}$ nas folhas, pode estar relacionada também com a baixa translocação desse nutriente na planta (Garcia et al., 1979; Martins et al., 2003). 
Dos cinco elementos químicos avaliados nas folhas, o $\mathrm{Ni}$ e o $\mathrm{Pb}$ foram os menos afetados pela adição de lodo de esgoto nos três cultivos de milho (Figura 1). Efeito significativo da aplicação de lodo no teor foliar de $\mathrm{Ni}$ só foi obtido para as parcelas adubadas com o $\mathrm{LF}$, no $2^{\circ}$ cultivo. Cabe ressaltar que, mesmo tendo sido significativo, o aumento no teor foliar de $\mathrm{Ni}$, proporcionado pela adição ao solo do $\mathrm{LF}$, foi muito pequeno, uma vez que a concentração de $\mathrm{Ni}$ na folha passou de 1,42 $\mathrm{mg} \mathrm{kg}^{-1}$, na dose 0 (testemunha), para $1,90 \mathrm{mg} \mathrm{kg}^{-1}$, na dose $8 \mathrm{LF}$. No caso do $\mathrm{Pb}$, no cultivo em que houve efeito significativo da aplicação das duas fontes de lodo de esgoto ( $2^{\circ}$ cultivo), verificou-se uma diminuição dos teores foliares nas doses mais altas aplicadas. A concentração de $\mathrm{Pb}$ nas folhas passou de 0,56 para $0,21 \mathrm{mg} \mathrm{kg}^{-1}$, nas doses 0 (testemunha) e $8 \mathrm{~N}$, respectivamente, nas parcelas adubadas com o $\mathrm{LB}$, e de 0,53 para $0,21 \mathrm{mg} \mathrm{kg}^{-1}$, nas doses 0 (testemunha) e $8 \mathrm{~N}$, respectivamente, nas parcelas adubadas com o LF. Estes resultados estão de acordo com os apresentados por Pierrisnard (1996), que verificou maior acúmulo de Ni nos sabugos, grãos e raízes, e de $\mathrm{Pb}$, nos sabugos e colmos de plantas de milho.

Com exceção do $1^{\circ}$ cultivo-LF, as adições de doses crescentes dos lodos de Franca e de Barueri promoveram incrementos lineares e significativos nos teores de Mn nas folhas de milho, sendo esses incrementos maiores no segundo e no terceiro cultivo. Nos dois últimos cultivos, para uma mesma dose de lodo, verificou-se uma tendência de ser o teor de $\mathrm{Mn}$ maior em folhas de milho cultivado na área adubada com o lodo de Franca (LF), em relação ao de Barueri (LB).

A redução nos teores foliares de $\mathrm{Mn}$ e Ni no $3^{\text {o }}$ cultivo pode ser explicada, em parte, pelo efeito da calagem realizada antes deste cultivo, provocando aumento do $\mathrm{pH}$ do solo e, conseqüentemente, redução da disponibilidade desses elementos para o milho. Esse possível efeito da calagem não foi observado para os demais metais pesados avaliados. De acordo com Borkert et al. (2001), o pH do solo é um dos principais fatores que controla a disponibilidade de Mn para as plantas, havendo redução no teor desse metal no tecido vegetal de espécies cultivadas em solo com $\mathrm{pH}$ superior a 5,5. Após o $3^{\circ}$ cultivo, foi realizada uma amostragem do solo em todas as parcelas experimentais, onde foi constatado que o $\mathrm{pH}$ (em água) médio do solo era de 5,8 , nas parcelas adubadas com o LB, e de 6,2, nas parcelas adubadas com o LF, valores esses acima dos preconizados por Borkert et al. (2001) para redução da disponibilidade de Mn. Reduções nos teores foliares de Mn e Ni também foram relatadas por Andersson \& Nilsson (1976) em nabo forrageiro cultivado em solo adubado com lodo de esgoto (19 $\mathrm{Mg} \mathrm{ha}^{-1}$, base seca), quando se adicionou $\mathrm{CaO}$ para elevação do $\mathrm{pH}$ do solo para 6,0. Conforme Wallace \& Wallace (1994), para que ocorra redução na disponibilidade de $\mathrm{Pb}$ para as plantas, o $\mathrm{pH}$ do solo precisa estar acima de 6,5, valor esse abaixo do observado no presente estudo $\left(\mathrm{pH}_{\text {água }}=\right.$ $5,9-6,2)$.

Em estudo realizado por Pombo (1995), em que foi avaliada a absorção de metais pesados $(\mathrm{Ni}, \mathrm{Pb}, \mathrm{Cd}$, $\mathrm{Zn} \mathrm{e} \mathrm{Cu}$ ) pelo azevém (Lolium multifloium) cultivado em solo adubado com lodo petroquímico, foi verificado que o $\mathrm{pH}$ foi o fator que mais contribuiu para a baixa absorção dos metais. Neste trabalho, no tratamento em que o pH do solo foi elevado para 7,5, ocorreu um decréscimo nos teores foliares de $\mathrm{Ni}, \mathrm{Pb}$ e $\mathrm{Cd}$, sendo este efeito não observado para $\mathrm{Zn}$ e Cu (Pombo, 1995). Segundo Soon (1981), essa redução na absorção dos metais pesados com o incremento do $\mathrm{pH}$ do solo ocorre pelo aumento da adsorção desses elementos às cargas dependentes de $\mathrm{pH}$ dos argilominerais, óxidoshidróxidos do solo e pelo acréscimo da constante de estabilidade do complexo metal-matéria orgânica, determinado pelo aumento da ionização de grupos funcionais, especialmente de $\mathrm{COOH}$, e pelo aumento da adsorção específica dos metais sobre as superfícies dos óxidos hidratados.

Os teores de $\mathrm{Zn}$ nas folhas de milho aumentaram de modo significativo, com resposta linear à aplicação das doses dos lodos de esgoto em todos os cultivos de milho, o que corrobora os resultados obtidos por Bidwell \& Dowdy (1987) e Martins et al. (2003). Dos metais avaliados, o Zn foi o que apresentou maior aumento nos teores foliares com a seqüência dos cultivos, o que, segundo Pierrisnard (1996), deve-se ao acúmulo preferencial do Zn em folhas de milho. Em geral, os teores foliares de $\mathrm{Zn}$ determinados neste estudo estiveram dentro da faixa considerada adequada para a cultura do milho, que é de 15 a $100 \mathrm{mg} \mathrm{kg}^{-1}$ (Cantarella et al., 1997). Os incrementos lineares nos teores foliares de $\mathrm{Zn}$ observados neste estudo podem ser uma resposta à alta concentração desse metal nos dois lodos e à aplicação sucessiva de doses elevadas dos mesmos, aumentando sua disponibilidade para o milho, mesmo nos cultivos onde foi realizada à calagem ( $1^{\circ}$ e $3^{\circ}$ cultivo).

Resultado semelhante foi encontrado por Hinesly et al. (1984), que, avaliando os efeitos da aplicação de lodo de esgoto em solo com acidez corrigida, verificaram incrementos na concentração de Zn nas folhas e grãos de milho, evidenciando que outros constituintes do lodo podem alterar os processos químicos que ocorrem no solo em tal extensão que a calagem passe a proporcionar pequena proteção contra a absorção desse metal pelas plantas. Os altos teores de $Z n$ verificados nas duas fontes de lodo e o incremento dos seus teores nas folhas com o acréscimo das doses aplicadas dos lodos, nos três cultivos, causam certa preocupação, uma vez que o uso continuado desse resíduo poderia contaminar o solo e as plantas com esse metal. Desse modo, há necessidade de reduzir o teor de Zn nos lodos de esgoto, o que pode ser alcançado pelo maior controle e físcalização, no entorno da ETE's, das atividades industriais e urbanas fontes desse metal. 
Comparando os resultados dos teores totais dos metais pesados em solo (Quadro 3) com os obtidos em folhas de milho, verificou-se que, para alguns dos metais avaliados, a partir de determinados teores totais em solo, não se observou acréscimo proporcional nos respectivos teores foliares, sugerindo uma resposta

\begin{tabular}{|c|c|c|}
\hline - $1^{\circ}$ cultivo & [ $2^{\circ}$ cultivo & $\Delta 3^{\circ}$ cultivo \\
\hline$\times \mathrm{AM}-1^{\circ}$ cultivo & * A M $-2^{\circ}$ cultivo & $+\mathrm{AM}-3^{\circ}$ cultivo \\
\hline
\end{tabular}

Lodo Barueri (LB)
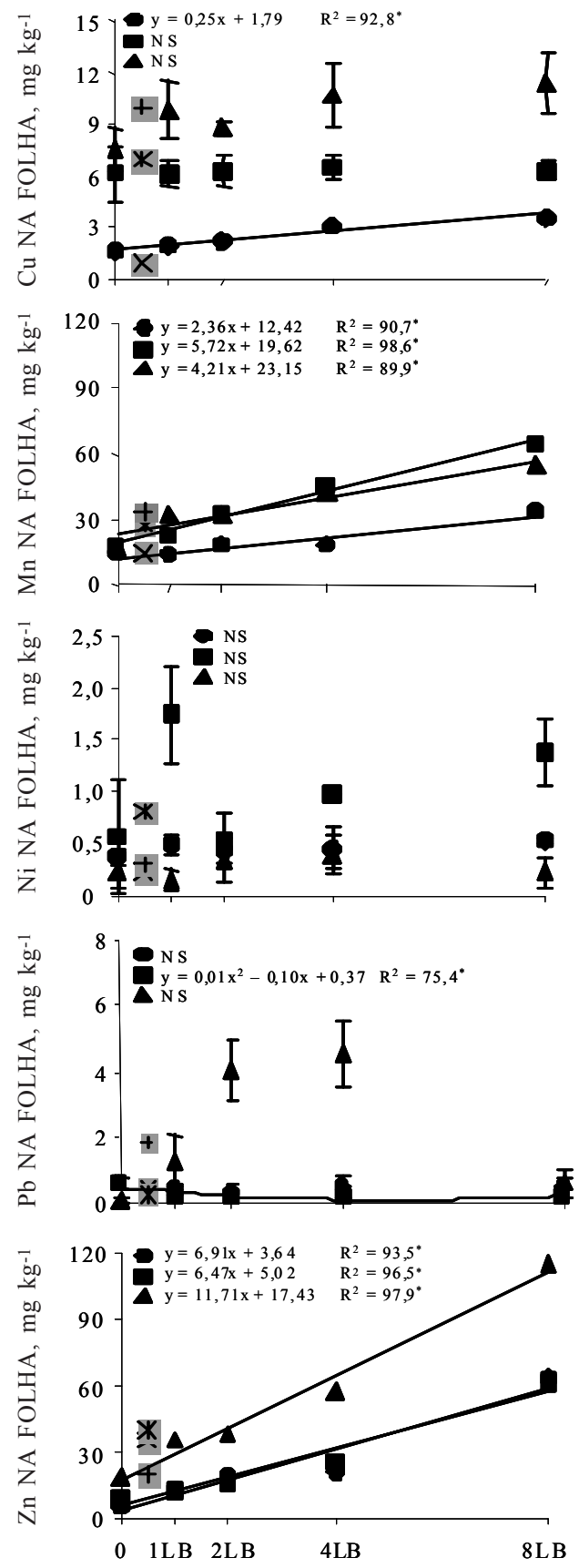

Lodo Franca (LF)
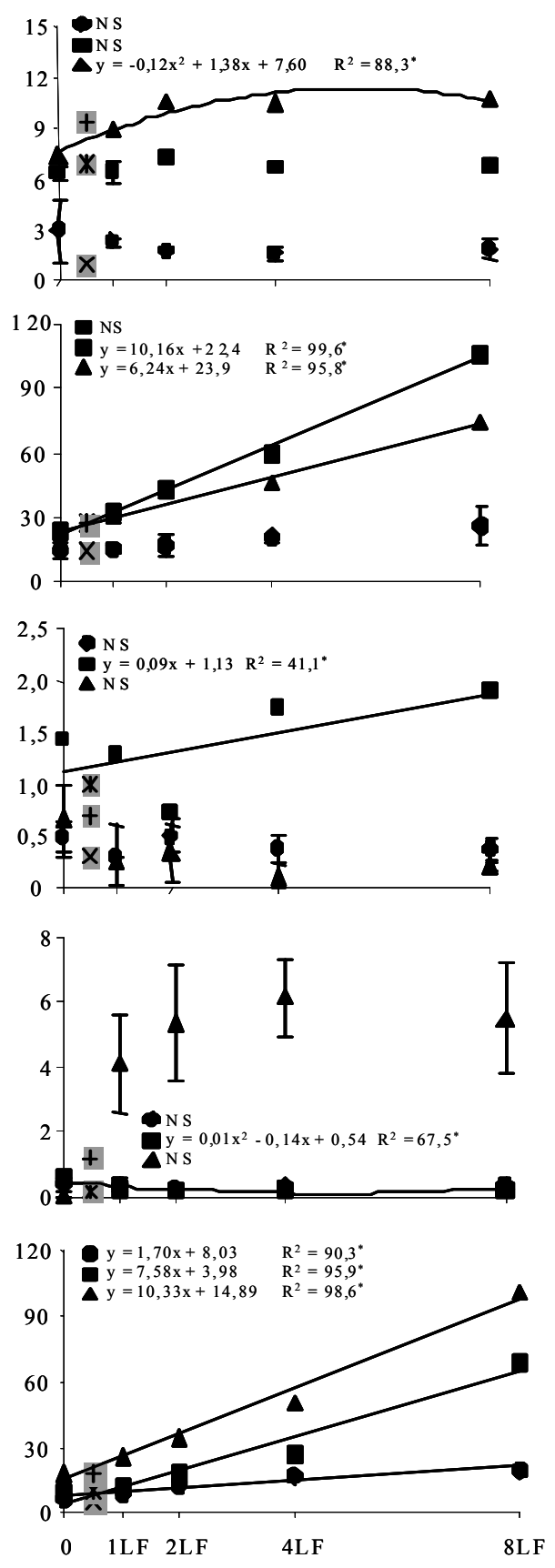

DOSE DE LODO DE ESGOTO COM BASE NO TEOR DE N

Figura 1. Efeito de diferentes fontes e doses de lodo de esgoto sobre os teores de $\mathrm{Cu}, \mathrm{Mn}, \mathrm{Ni}, \mathrm{Pb}$ e $\mathrm{Zn}$ em folhas de milho, em três cultivos consecutivos (* Modelo ajustado significativo a p $\leq 0,05$ pelo teste F; NS - não-significativo; AM = adubação mineral com NPK recomendada para a cultura do milho). As barras verticais referem-se ao desvio-padrão da média. 
do tipo platô. Esse efeito foi observado para o $\mathrm{Cu}\left(3^{\circ}\right.$ cultivo-LF e $1^{\circ}$ cultivo- $\left.\mathrm{LB}\right), \mathrm{Mn}\left(1^{\circ}\right.$ cultivo- $\left.\mathrm{LB}\right), \mathrm{Pb}\left(1^{\circ}\right.$ e $3^{\circ}$ cultivo- $\left.\mathrm{LB}\right), \mathrm{Ni}\left(1^{\circ}\right.$ cultivo-LB) e $\mathrm{Zn}\left(1^{\circ}\right.$ cultivo-LB), o que está de acordo com os resultados obtidos para esses mesmos metais pesados em estudos com as culturas do milho (Logan et al., 1997) e da cana-deaçúcar (Oliveira \& Mattiazzo, 2001) cultivadas em solos adubados com lodo de esgoto.

Todavia, ao contrário do relatado nos estudos de Logan et al. (1997) e Oliveira \& Mattiazzo (2001), no presente trabalho, não foi alcançado o platô para todos os metais pesados e em todos os cultivos de milho. Merece destaque o fato de que as doses de lodo aplicadas nos estudos descritos anteriormente foram menores do que as avaliadas no presente trabalho, o que favorece a estabilização dos teores foliares, em razão do menor aporte de metais pesados ao solo. Outro ponto a ser considerado é que, na maioria dos trabalhos em que este efeito foi verificado, as doses são aplicadas somente durante um ano agrícola. Além disso, os estudos citados foram realizados em casa de vegetação durante curto período de tempo. Esses fatores devem ser considerados quando se comparam resultados obtidos sob diferentes condições experimentais.

A realização em campo de pesquisas em longo prazo adquire importância, principalmente, quando se busca estudar a dinâmica dos metais pesados adicionados aos solos de acordo com o uso de doses elevadas de lodo, visando verificar a possibilidade de acúmulo desses elementos em solos e plantas. Experimentos dessa natureza fornecem subsídios para a elaboração de normas que regulem o uso do lodo de esgoto em solos brasileiros, uma vez que esses estudos são escassos nas condições de clima e solos do Brasil, onde existe grande potencial para utilizar o lodo de esgoto na adubação das lavouras.

\section{Teores de metais pesados em grãos}

Os resultados referentes aos teores de metais pesados em grãos de milho, no primeiro cultivo, não serão apresentados neste estudo, pois estiveram abaixo do limite de determinação do protocolo analítico utilizado.

Segundo a Associação Brasileira das Indústrias da Alimentação - ABIA (ABIA, 1985), os limites máximos de $\mathrm{Cu}, \mathrm{Ni}, \mathrm{Pb}$ e $\mathrm{Zn}$ permitidos em grãos (matéria seca) de cereais são de 30, 5,0, 8,0 e $50 \mathrm{mg} \mathrm{kg-1}$, respectivamente. Kabata-Pendias \& Pendias (2001) estabeleceram, como faixa crítica de Mn em grãos produzidos em locais contaminados com esse metal, os teores entre 15 e $80 \mathrm{mg} \mathrm{kg}^{-1}$. Em nenhum momento, esses teores foram alcançados nos grãos obtidos nos diferentes tratamentos do presente estudo (Figura 2).

Os teores de $\mathrm{Cu}, \mathrm{Mn}$, Ni e Zn em grãos (Figura 2) apresentaram comportamento similar ao observado em tecido foliar (Figura 1), com a seqüência dos cultivos de milho.

As plantas de milho que se desenvolveram nas parcelas adubadas com o LF não apresentaram

Quadro 3. Teores totais de $\mathrm{Cu}, \mathrm{Mn}, \mathrm{Ni}, \mathrm{Pb}$ e $\mathrm{Zn}$ em Latossolo adubado com doses crescentes dos lodos de esgoto produzidos nas ETE's de Barueri e Franca (SP) e cultivado com milho, em três cultivos consecutivos

\begin{tabular}{|c|c|c|c|c|c|c|c|c|c|c|c|c|c|c|c|}
\hline \multirow{2}{*}{ Tratamento } & \multicolumn{3}{|c|}{$\mathrm{Cu}$} & \multicolumn{3}{|c|}{ Mn } & \multicolumn{3}{|c|}{$\mathrm{Ni}$} & \multicolumn{3}{|c|}{$\mathbf{P b}$} & \multicolumn{3}{|c|}{$\mathrm{Zn}$} \\
\hline & $1^{\circ}$ & $2^{\circ}$ & $3^{\circ}$ & $1^{\circ}$ & $2^{\circ}$ & $3^{\circ}$ & $1^{\circ}$ & $2^{\circ}$ & $3^{\circ}$ & $1^{\circ}$ & $2^{\circ}$ & $3^{\circ}$ & $1^{\circ}$ & $2^{\circ}$ & $3^{\circ}$ \\
\hline
\end{tabular}

\begin{tabular}{|c|c|c|c|c|c|c|c|c|c|c|c|c|c|c|c|}
\hline \multirow[b]{2}{*}{$\mathrm{T}$} & \multicolumn{15}{|c|}{ Lodo de Barueri (LB) } \\
\hline & 13,6 & 11,6 & 15,7 & 73,2 & 67,3 & 72,3 & 8,9 & 10,7 & 7,6 & 10,5 & 13,4 & 16,0 & 11,6 & 11,4 & 14,0 \\
\hline $\mathrm{AM}$ & 12,6 & 10,6 & 34,6 & 63,8 & 69,0 & 64,9 & 8,2 & 10,0 & 7,1 & 8,0 & 14,5 & 10,1 & 14,3 & 21,8 & 13,7 \\
\hline $1 \mathrm{LB}$ & 18,8 & 14,5 & 18,2 & 69,2 & 75,7 & 56,7 & 11,4 & 12,2 & 8,0 & 10,9 & 16,3 & 10,4 & 20,3 & 22,0 & 20,6 \\
\hline $2 \mathrm{LB}$ & 14,8 & 25,8 & 32,2 & 69,9 & 67,1 & 66,2 & 10,4 & 12,3 & 9,5 & 11,0 & 14,3 & 13,2 & 25,5 & 33,5 & 32,7 \\
\hline $4 \mathrm{LB}$ & 31,4 & 26,1 & 44,6 & 62,2 & 69,1 & 69,4 & 14,9 & 17,3 & 13,6 & 9,9 & 17,9 & 15,8 & 70,6 & 74,6 & 53,0 \\
\hline \multirow[t]{2}{*}{$8 \mathrm{LB}$} & 56,0 & 38,9 & 61,1 & 65,6 & 68,1 & 65,5 & 21,3 & 22,3 & 18,3 & 17,8 & 16,3 & 15,6 & 101,4 & 85,8 & 89,1 \\
\hline & \multicolumn{15}{|c|}{ Lodo de Franca (LF) } \\
\hline $\mathrm{T}$ & 11,0 & 8,9 & 14,9 & 70,8 & 69,8 & 49,0 & 8,0 & 8,8 & 5,1 & 9,8 & 11,4 & 7,4 & 11,6 & 11,6 & 9,7 \\
\hline $\mathrm{AM}$ & 11,4 & 13,9 & 41,9 & 71,1 & 73,4 & 73,3 & 8,2 & 9,6 & 7,5 & 10,2 & 11,7 & 9,5 & 13,8 & 22,5 & 15,9 \\
\hline $1 \mathrm{LF}$ & 11,1 & 10,0 & 26,0 & 70,8 & 74,3 & 72,8 & 8,0 & 8,5 & 8,0 & 10,1 & 7,7 & 10,2 & 12,4 & 13,1 & 18,7 \\
\hline $2 \mathrm{LF}$ & 10,8 & 16,5 & 17,8 & 68,8 & 74,4 & 71,7 & 7,7 & 10,3 & 7,9 & 8,0 & 12,9 & 10,2 & 15,6 & 19,1 & 21,5 \\
\hline $4 \mathrm{LF}$ & 14,3 & 13,7 & 43,2 & 73,9 & 67,5 & 74,3 & 10,2 & 9,4 & 8,3 & 10,0 & 12,4 & 12,7 & 22,5 & 19,4 & 27,1 \\
\hline $8 \mathrm{LF}$ & 15,7 & 13,9 & 58,9 & 75,3 & 65,1 & 69,3 & 12,6 & 10,9 & 8,3 & 10,3 & 11,9 & 13,0 & 24,7 & 26,9 & 39,4 \\
\hline
\end{tabular}

(1) $\mathrm{T}=$ testemunha absoluta; $\mathrm{AM}=$ adubação mineral (NPK); $1 \mathrm{LF}$ e $1 \mathrm{LB}=$ doses dos lodos de esgoto para fornecer a mesma quantidade de $\mathrm{N}$ do tratamento $\mathrm{AM} ; 2 \mathrm{LF}$ e $2 \mathrm{LB}=$ dois; $4 \mathrm{LF}$ e $4 \mathrm{LB}=$ quatro e $8 \mathrm{LF}$ e $8 \mathrm{LB}=$ oito vezes a dose dos lodos de esgoto descrita no tratamento $1 \mathrm{LF}$ e $1 \mathrm{LB}$. 
incrementos significativos nos teores de $\mathrm{Cu}$ nos grãos. Nas parcelas adubadas com o LB, houve efeito significativo apenas no $3^{\circ}$ cultivo, sendo observada uma diminuição nos teores de $\mathrm{Cu}$ nos grãos com o incremento das doses aplicadas. No presente estudo, não foi notada remobilização do $\mathrm{Cu}$ das folhas para os

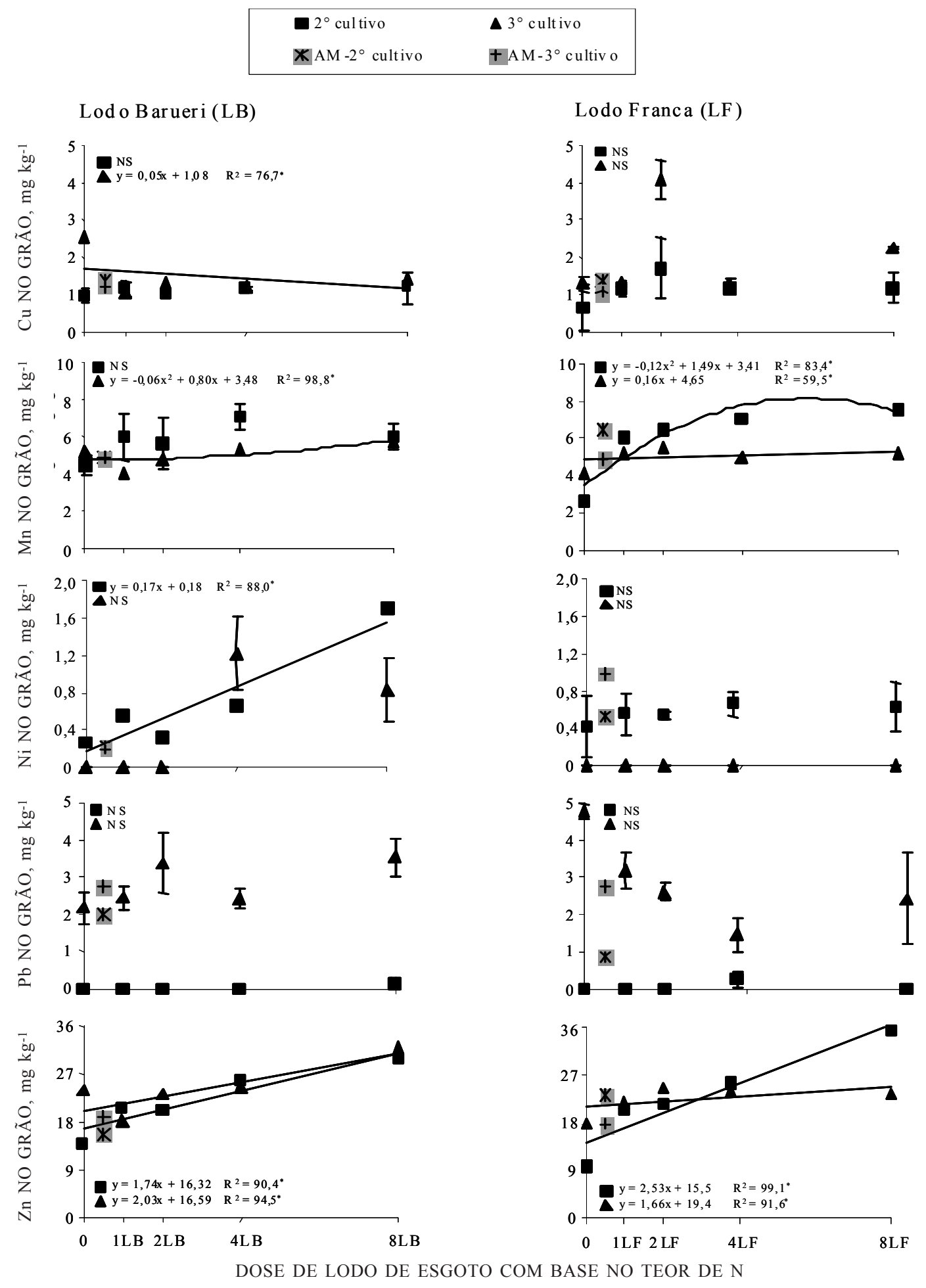

Figura 2. Efeito de diferentes fontes e doses de lodo de esgoto sobre os teores de $\mathrm{Cu}, \mathrm{Mn}, \mathrm{Ni}, \mathrm{Pb}$ e $\mathrm{Zn}$ em grãos de milho, em dois cultivos consecutivos (* Modelo ajustado significativo a p $\leq 0,05$, pelo teste F; NS - nãosignificativo; $\mathrm{AM}$ = adubação mineral com NPK recomendada para a cultura do milho). As barras verticais referem-se ao desvio-padrão da média. 
grãos de milho, já que o acréscimo de $\mathrm{Cu}$ no tecido foliar não se manifestou nos grãos (Figuras 1 e 2).

Quando se utilizou o LF, os teores de Mn em grãos aumentaram progressivamente com o incremento das doses de lodo, nos dois cultivos avaliados, sendo esse padrão de resposta verificado em áreas adubadas com o LB somente no $3^{\circ}$ cultivo de milho. Os teores de $\mathrm{Mn}$ em grãos de milho variaram de $7,5 \mathrm{mg} \mathrm{kg}^{-1}$ ( $2^{\circ}$ cultivo) a $5,9 \mathrm{mg} \mathrm{kg}^{-1}$ ( $3^{\circ}$ cultivo), quando se aplicou o $\mathrm{LF}$, e de $7,1 \mathrm{mg} \mathrm{kg}^{-1}$ ( $2^{\circ}$ cultivo) a $5,7 \mathrm{mg} \mathrm{kg}^{-1}$ ( $3^{\circ}$ cultivo), quando o LB foi adicionado ao solo. Esses resultados indicam que, mesmo o LB apresentando quase duas vezes mais $\mathrm{Mn}$ que o $\mathrm{LF}$, isto não se refletiu num maior teor em grãos desse metal pesado.

A incorporação das duas fontes de lodo de esgoto exerceu pequena influência sobre os teores de Ni nos grãos de milho, pois a resposta a esse metal foi significativa apenas no $2^{\circ}$ cultivo-LB (Figura 2 ). Dessa forma, embora a concentração de Ni no LB estivesse acima dos valores máximos permitidos (CETESB, 1999), esse elemento químico foi pouco absorvido pelas plantas, não atingindo em nenhum tratamento o nível crítico de toxidez $\left(5,0 \mathrm{mg} \mathrm{kg}^{-1}\right)$ sugerido pela ABIA (1985). Outro fator a ser considerado é que os teores de $\mathrm{Ni}$ em grãos de milho foram maiores no $2^{\circ}$ cultivo para as duas fontes de lodo, resultado semelhante ao observado para folhas, indicando a maior disponibilidade desse metal, em solo, em cultivos não precedidos de calagem.

De modo similar ao observado para as folhas, houve uma diminuição nos teores de $\mathrm{Mn}$ e Ni em grãos no $3^{\circ}$ cultivo. Mesmo não sendo objetivo deste estudo, acredita-se que a aplicação de calcário antes do último cultivo possa estar relacionada com a diminuição de $12 \%$ do Mn e $20 \%$ do Ni nas folhas das plantas de milho adubadas com o LB. Para esta mesma fonte de lodo, a redução dos teores em grãos foi de 12 e $41 \%$, para o $\mathrm{Mn}$ e Ni, respectivamente. Nas parcelas adubadas com o LF, a redução foi mais expressiva, tendo sido, para o $\mathrm{Mn}$, as reduções de 20 e $16 \%$, e para o $\mathrm{Ni}$, de 75 e $95 \%$, respectivamente, para as folhas e grãos.

Já para o $\mathrm{Pb}$, os teores em grãos foram maiores no $3^{\circ}$ cultivo. Berton (1992) ressalta que os teores de $\mathrm{Pb}$ encontrados nos grãos são muito baixos, da ordem de $0,5 \mathrm{mg} \mathrm{kg}^{-1}$ de matéria seca. Apesar de os teores de $\mathrm{Pb}$ nos grãos, no terceiro ciclo de cultivo do milho, estarem acima dos valores citados por Berton (1992), os teores determinados neste estudo mostraram-se abaixo do limite máximo $\left(8,0 \mathrm{mg} \mathrm{kg}^{-1}\right)$ estabelecido para grãos de cereais (ABIA, 1985), para as duas fontes de lodo avaliadas.

Mesmo na dose mais elevada dos lodos, correspondente a oito vezes à dose recomendada de $\mathrm{N}$ para o milho, os teores de $\mathrm{Zn}$ nos grãos no $2^{\circ}$ cultivo (35,4 e 29,9 $\mathrm{mg} \mathrm{kg}^{-1}$, respectivamente, para LF e LB) e, no $3^{\text {o }}$ cultivo (23,6 e $32,2 \mathrm{mg} \mathrm{kg}^{-1}$, respectivamente, para LF e LB) estiveram abaixo do limite estabelecido pela ABIA (1985). O Zn foi, dos metais avaliados, o que apresentou resposta significativa e linear nos teores determinados em folhas e grãos de milho de acordo com a aplicação das doses crescentes das duas fontes de lodo de esgoto. Considerando que o aumento dos teores de Zn nos compartimentos vegetais do milho (folha e grãos) deveu-se unicamente à aplicação dos lodos, calcula-se que a quantidade desse metal determinado nas folhas e nos grãos, na maior dose aplicada (8LF e 8LB), representou, em média, 0,0004 e $0,0001 \%$ da quantidade fornecida pelos lodos de Franca e Barueri, respectivamente. Este comportamento está de acordo com o observado por Chang et al. (1987), que verificaram que as quantidades de metais pesados absorvidas pelas plantas, em áreas adubadas com lodo de esgoto, são pequenas e geralmente inferiores a $1 \%$ da quantidade adicionada pelo resíduo. Entretanto, é preciso levar em conta que, neste estudo, foram levantadas informações referentes a apenas três aplicações sucessivas de lodo e, mesmo nesse curto espaço de tempo, as aplicações dos lodos de esgoto foram suficientes para proporcionar teores de Zn em grãos próximos ao limite estabelecido pela ABIA (1985).

Considerando os teores de metais pesados em folhas e grãos de milho, verificou-se que as diferentes partes da planta comportaram-se de forma distinta em relação às quantidades de metais armazenadas. Os resultados evidenciaram o maior teor dos metais nas folhas, em relação aos grãos de milho, resultados também observados por Martins et al. (2003). As maiores diferenças foram observadas para o $\mathrm{Mn}$, com teores em folha $816 \%$ ( $2^{\circ}$ cultivo) e $729 \%$ ( $3^{\circ}$ cultivo) superiores em relação aos grãos, nas parcelas adubadas com o LF. Esses resultados são de grande relevância, uma vez que, não sendo verificados efeitos tóxicos às plantas, os grãos são o produto industrial do milho nos quais os teores de metais pesados poderiam causar problemas em curto prazo.

Mesmo não sendo observados teores de $\mathrm{Cu}, \mathrm{Mn}$, $\mathrm{Ni}, \mathrm{Pb}$ e $\mathrm{Zn}$ nas folhas e grãos de milho acima dos limites estabelecidos em literatura, foi verificada uma tendência de aumento nos teores desses metais com a seqüência dos cultivos, o que evidencia a importância da continuidade dos estudos em campo por um maior período de tempo, com vistas em averiguar se esse padrão de resposta será mantido ao longo do tempo, ou se haverá uma estabilização a partir de determinado teor nas plantas ou de doses dos lodos aplicadas.

\section{CONCLUSÕES}

1. Os teores de Mn e Zn em folhas e grãos de milho foram incrementados com a seqüência de aplicações anuais sucessivas dos lodos de esgoto de Barueri e Franca. 
2. Mesmo com três aplicações sucessivas dos lodos de esgoto, os teores de $\mathrm{Mn}, \mathrm{Ni}, \mathrm{Pb}$ e $\mathrm{Zn}$ permaneceram abaixo dos limites considerados tóxicos para as folhas de milho.

3. As folhas apresentaram maiores teores de metais pesados do que os grãos, o que implica maior possibilidade de transferência de metais para a cadeia alimentar, caso essa parte da planta seja consumida.

4. Os teores de metais pesados nos grãos, até à terceira aplicação sucessiva dos lodos de esgoto, permaneceram dentro da faixa considerada aceitável para o consumo humano.

\section{AGRADECIMENTOS}

Ao Dr. Celso Vainer Manzatto, Marcelo Saldanha e Viviane Scaleira da Embrapa Solos, pelo apoio às ações de pesquisa deste estudo e pela ajuda nas análises laboratoriais; ao Engenheiro-Agrônomo José A. H. Galvão da Embrapa Meio Ambiente, pela ajuda constante na coleta e preparo de amostras e na manutenção do experimento em campo.

\section{LITERATURA CITADA}

ABREU, M.F.; ABREU, C.A. \& ANDRADE, J.C. Determinação de fósforo, potássio, cálcio, magnésio, enxofre, cobre, ferro, manganês, zinco, níquel, cádmio, cromo e chumbo em ácido nítrico usando métodos da US-EPA. In: RAIJ, B. van; ANDRADE, J.C.; CANTARELLA, H. \& QUAGGIO, J.A., eds. Análise química para avaliação da fertilidade de solos tropicais. Campinas, Instituto Agronômico de Campinas, 2001. p.251-261.

ANDERSSON, A. \& NILSSON, K.O. Influence on the levels of heavy metals in soil and plant sewage sludge used as fertilizer. J. Agric. Res., 61:151-159, 1976.

AMERICAN PUBLIC HEALTH ASSOCIATION - APHA. AMERICAN WATER WORKS ASSOCIATION- AWWA; WATER POLLUTION CONTROL FEDERATION WPCF. Standard methods for the examination of water and wastewater. 18.ed. Washington, 1992.

ASSOCIAÇÃO BRASILEIRA DAS INDUSTRIAS DA ALIMENTAÇÃO - ABIA. Compêndio da legislação dos alimentos. São Paulo, 1985. Não publicado.

BERTON, R.S. Fertilizantes e poluição. In: REUNIÃO BRASILEIRA DE FERTILIDADE DO SOLO E NUTRIÇÃO DE PLANTAS, 20., Piracicaba, 1992. Anais. Piracicaba, Fundação Cargill, 1992. 425p.

BERTONCINI, E.I. Comportamento de $\mathrm{Cd}, \mathrm{Cr}, \mathrm{Cu}, \mathrm{Ni}$ e $\mathrm{Zn}$ em Latossolos sucessivamente tratados com biossólido: Extração seqüencial, fitodisponibilidade e caracterização de substâncias húmicas. Piracicaba, Escola Superior de Agricultura "Luiz de Queiroz", 2002. 195p. (Tese de Doutorado)
BIDWELL, A.M. \& DOWDY, R.H. Cadmium and zinc availability to corn following termination of sewage sludge applications. J. Environ. Qual., 16:438-442, 1987.

BORKERT, C.M.; PAVAN, M.C. \& BATAGLIA, O.C. Disponibilidade e avaliação de elementos catiônicos: Ferro e manganês. In: FERREIRA, M.E.; CRUZ, M.C.P.; RAIJ, B.van. \& ABREU, C.A., eds. Micronutrientes e elementos tóxicos na agricultura. Jaboticabal, CNPq/FAPESP/ POTAFOS, 2001. p.151-185.

BREMNER, J.M. Nitrogen-total. In: SPARKS, D.L.; PAGE, A.L.; HELMKE, P.A.; LOEPPERT, R.H.; SOLTANPOUR, P.N.; TABATABAI, M.A.; JOHNSTON, C.T. \& SUMNER, M.E., eds. Methods of soil analysis. Chemical Methods. Madison, Soil Science Society of America, 1996. p.10851121.

CANTARELlA, H.; RAIJ, B. van. \& CAMARGO, C.E.O. Cereais. In: RAIJ, B. van; CANTARELLA, H.; QUAGGIO, J.A. \& FURLANI, A.M.C., eds. Recomendações de adubação e calagem para o Estado de São Paulo. 2.ed. Campinas, Instituto Agronômico de Campinas/Fundação IAC, 1997. p.45-71.

CHANG, A.C.; HINESLY, T.D.; BATES, T.E.; DONER, H.E.; DOWDY, R.H. \& RYAN, J.A. Effects of long term sludge application on accumulation of trace elements by crops. In: PAGE, A.L.; LOGAN, T.J. \& RYAN, J.A., eds. Land application of sludge: food chain implications. Chelsea, Lewis Publishers, 1987. p.53-66.

CHANG, A.C.; HYUN, H. \& PAGE, A.L. Cadmium uptake for Swiss chard grown on composted sewage sludge treated field plots: Plateau or time bomb? J. Environ. Qual., 26:1119, 1997.

COMPANHIA DE TECNOLOGIA DE SANEAMENTO AMBIENTAL - CETESB. Aplicação de lodos de sistemas de tratamento biológico em áreas agrícolas: critérios para projeto e operação. São Paulo, 1999, 32p. (Manual Técnico, 4230)

COREY, R.B.; KING, L.D.; LUE-HING, C.; FANNING, D.S.; STREET, J.J. \& WALKER, J.M. Effects of sludge properties on accumulations of trace elements by crops. In: PAGE, A.L.; LOGAN, T.J. \& RYAN, J.A., eds. Land application of sludge: Food chain implications. Chelsea, Lewis Publishers, 1987. p.25-51.

FAQUIN, V. Nutrição mineral de plantas. Lavras, Universidade Federal de Lavras, 2001. 182p.

FERREIRA, D.F. Análises estatísticas por meio do Sisvar para Windows 4.0. In: REUNIÃO ANUAL DA REGIÃO BRASILEIRA DA SOCIEDADE INTERNACIONAL DE BIOMETRIA, 45., São Carlos, 2000. Anais. São Carlos, Universidade Federal de São Carlos, 2000. p.255-258.

GARCIA, W.J.; BLESSIN, C.W.; SANFORD, H.W. \& INGLETT, G.E. Translocation and accumulation of seven heavy metals in tissues of corn plant grown on sludge-treated strip-mined soil. J. Agric. Food Chem., 27:1088-1094, 1979.

GARDINER, D.T.; MILLER, R.W.; BADAMCHIAN, B.; AZZARI, A.S. \& SISSON, D.R. Effects of repeated sewage sludge applications on plant accumulation of heavy metals. Agric. Ecosys. Environ., 55:1-6, 1995. 
HINESLY, T.D.; REDBORG, K.E.; PIETZ, R.I. \& ZIEGLER, E.L. Cadmium and zinc uptake by corn (Zea mays L.) with repeated applications of sewage sludge. J. Agric. Food Chem., 32:155-163, 1984.

INTERNATIONAL ORGANIZATION FOR STANDARDISATION - ISO. Soil quality, extraction of trace elements soluble in aqua regia, ISO 11466, 1995.

JING, J. \& LOGAN, T.J. Effects of sewage sludge cadmium concentration on chemical extractability and plant uptake. J. Environ. Qual., 21:73-81, 1992.

KABATA-PENDIAS, A. \& PENDIAS, H. Trace elements in soils and plants. 3.ed. Boca Raton, CRC Press, 2001. 413p.

LOGAN, T.J.; LYNDSAY, B.J.; GOINS, L.E. \& RYAN, J.A. Field assessment of sludge metal bioavailability to crops: sludge rate response. J. Environ. Qual., 26:534-550, 1997.

LOGAN, T.J. \& CHANEY, L.R. Metals. In: WORKSHOP ON UTILIZATION OF MUNICIPAL WASTEWATER AND SLUDGE ON LAND, 1., Riverside, 1983. Proceedings. Riverside, University of California, 1983. p.235-323.

MARTINS, A.L.C.; BATAGLIA, O.C.; CAMARGO, O.A. \& CANTARELLA, H. Produção de grãos e absorção de $\mathrm{Cu}$, $\mathrm{Fe}, \mathrm{Mn}$ e $\mathrm{Zn}$ pelo milho em solo adubado com lodo de esgoto, com e sem calcário. R. Bras. Ci. Solo, 27:563-574, 2003.

McBRIDE, M.B. Toxic metal accumulation from agricultural use of sludge: Are USEPA regulations protective? J. Environ. Qual., 24:5-18, 1995.

NELSON, D.W. \& SOMMERS, L.E. Total carbon, organic carbon, and organic matter. In: PAGE, A.L., MILLER, R.H. \& KEENEY, D.R., eds. Methods of soil analysis. 2.ed. Madison, American Society of Agronomy/Soil Science Society of America, 1982. p.539-579.
OLIVEIRA, F.C. \& MATTIAZZO, M.E. Metais pesados em Latossolo tratado com lodo de esgoto e em plantas de cana-de-açúcar. Sci. Agric., 58:581-593, 2001.

PAGE, A.L.; LOGAN, T.J. \& RYAN, J.A. Land application of sludge-food chain implications. Chelsea, Lewis Publishers, 1987. 168p.

PIERRISNARD, F. Impact de l' amedment dês boues residuaires de la ville de Marseille sur de sols a vocation agricole: comportment du $\mathrm{Cd}, \mathrm{Cr}, \mathrm{Cu}, \mathrm{Ni}, \mathrm{Pb}$ e $\mathrm{Zn}$, des hydrocarbures et des composes polares. Marseille, Université de Marseille, 1996. 408p. (Tese de Doutorado)

POMBO, L.C.A. Absorção de metais pesados pelo azevém (Lolium multiflorum) em dois solos do Estado do Rio Grande do Sul. Pesq. Agropec. Bras., 30:1217-1224, 1995.

RAIJ, B. van.; CANTARELLA, H.; QUAGGIO, J.A. \& FURLANI, A.M.C. Recomendações de adubação e calagem para o Estado de São Paulo. Campinas, Instituto Agronômico de Camoinas, 1997. 285p.

SILVA, F.C., ed. Manual de análises químicas de solos, plantas e fertilizantes. Brasília, Embrapa Comunicação para Transferência de Tecnologia, 1999. 370p.

SOON, Y.K. Solubility and sorption of cadmium in soils amended with sewage sludge. J. Soil. Sci., 32:85-95, 1981.

TEDESCO, M.J.; GIANELLO, C.; BISSANI, C.A.; BOHEN, H. \& VOLKWEISS, S.J. Análise de solo, plantas e outros materiais. Porto Alegre, Universidade Federal Rio Grande do Sul, 1995. 174p.

WALLACE, A. \& WALLACE, G.A. A possible flaw in EPA'S 1993 new sludge rule due to heavy metal interaction. Comm. Soil Sci. Plant Anal., 25:129-135, 1994.

WEBBER, M.D.; KLOKE, A. \& JELL, J.C. A review of current sludge use guidelines for the control of heavy metal contamination in soils. In: L'HERMITE, P. \& OTT, H., eds. Processing and use of sewage sludge. 3.ed. Dordrecht, Reidel, 1984. p.371-386. 